\title{
Percutaneous left atrial appendage closure using the LAmbre device. First clinical results in Poland
}

\author{
Marian Burysz ${ }^{1}$, Radosław Litwinowicz², Magdalena Bryndza², Radomir Skowronek ${ }^{1}$, Wojciech Ogorzeja ${ }^{1}$, \\ Krzysztof Bartus²
}

${ }^{1}$ Department of Cardiac Surgery, Regional Specialist Hospital, Grudziadz, Poland

${ }^{2}$ Department of Cardiovascular Surgery and Transplantology, Institute of Cardiology, Jagiellonian University Medical College, Krakow, Poland

Adv Interv Cardiol 2019; 15, 2 (56): 251-254

DOI: https://doi.org/10.5114/aic.2019.86019

\section{Introduction}

In adult populations, atrial fibrillation (AF) is the major arrhythmia and successful treatment rates are low [1]. In recent years, left atrial appendage occlusion (LAAO) has become an alternative method for stroke prevention in patients in whom oral anticoagulation (OAC) is ineffective or contraindicated or in patients with life-threatening complications [2, 3]. Previous studies have demonstrated that the LAAO procedure is safe and effective in the prevention of thromboembolic events, including in high risk patients [4-10].

In the medical market, there are a number of available devices including endocardial and epicardial devices $[4,5,9]$. However, in some cases, the anatomy of the left atrial appendage (LAA) may constitute a contraindication to implantation of these devices. The LAmbre device is a novel system, designed especially for LAA closure when problematic morphology is present $[11,12]$.

\section{Aim}

Herein, we present the first use of the LAmbre device in Poland in patients with AF.

\section{Material and methods}

A retrospective, single-center study was performed in 24 consecutive patients with non-valvular AF, who underwent LAAO with the LAmbre device (Lifetech Scientific Corp., Shenzhen, China) between 2016 and 2018 (Figure 1). The LAmbre occluder system was previously described [13]. LAmbre device selection was based on operators' decision. All procedures were performed under general anesthesia. Patient characteristics are presented in Table I. The LAA anatomy was assessed with computed tomogra- phy angiography before each procedure. Oral anticoagulation therapy was discontinued and unfractionated heparin was used during the procedure. After the procedure, aspirin (75 mg/dose/day) and clopidogrel (75 mg/dose/ day) for 6 months were recommended in each patient. Leak was defined as the presence of flow from the left atrium to the LAA $<3 \mathrm{~mm}[14]$.

Follow-up visits, including transesophageal echocardiography, were performed at 3 and 6 months post-procedure. Data on mortality, causes of mortality and serious adverse events (SAE) were collected.

\section{Statistical analysis}

Data are expressed as mean \pm standard deviation or median (interquartile range; Q1 $-25^{\text {th }}$ percentile and Q3 - $75^{\text {th }}$ percentile), unless otherwise stated. Categorical variables were expressed as counts and percentages.

\section{Results}

All procedures were successfully completed with no perioperative complications. The LAAO procedure or device related mortality was $0 \%$. The mean time for the procedure was $62.92 \pm 14.21 \mathrm{~min}$. Eleven different sizes of occluder were implanted during the procedures, depending on the size and shape of the left atrial appendage. The choice of device size was made by the operator during the procedure based on intraprocedural transesophageal echocardiography (TEE) examination. There was a $100 \%$ success rate with no complications. No post-procedural leaks were observed. Half of the patients were discharged from hospital on the second or third day following the procedure.

The overall follow-up was 349 months. During the follow-up period, there were 4 (16.7\%) deaths; 1 case with

\section{Corresponding author:}

Radosław Litwinowicz MD, PhD, Department of Heart, Vascular and Transplantology, Institute of Cardiology, Jagiellonian University Medical College, Prądnicka St, 31-202 Krakow, Poland, phone: +48 1261430 75, e-mail: litwa2@poczta.onet.pl

Received: 6.12.2018, accepted: 28.02.2019. 

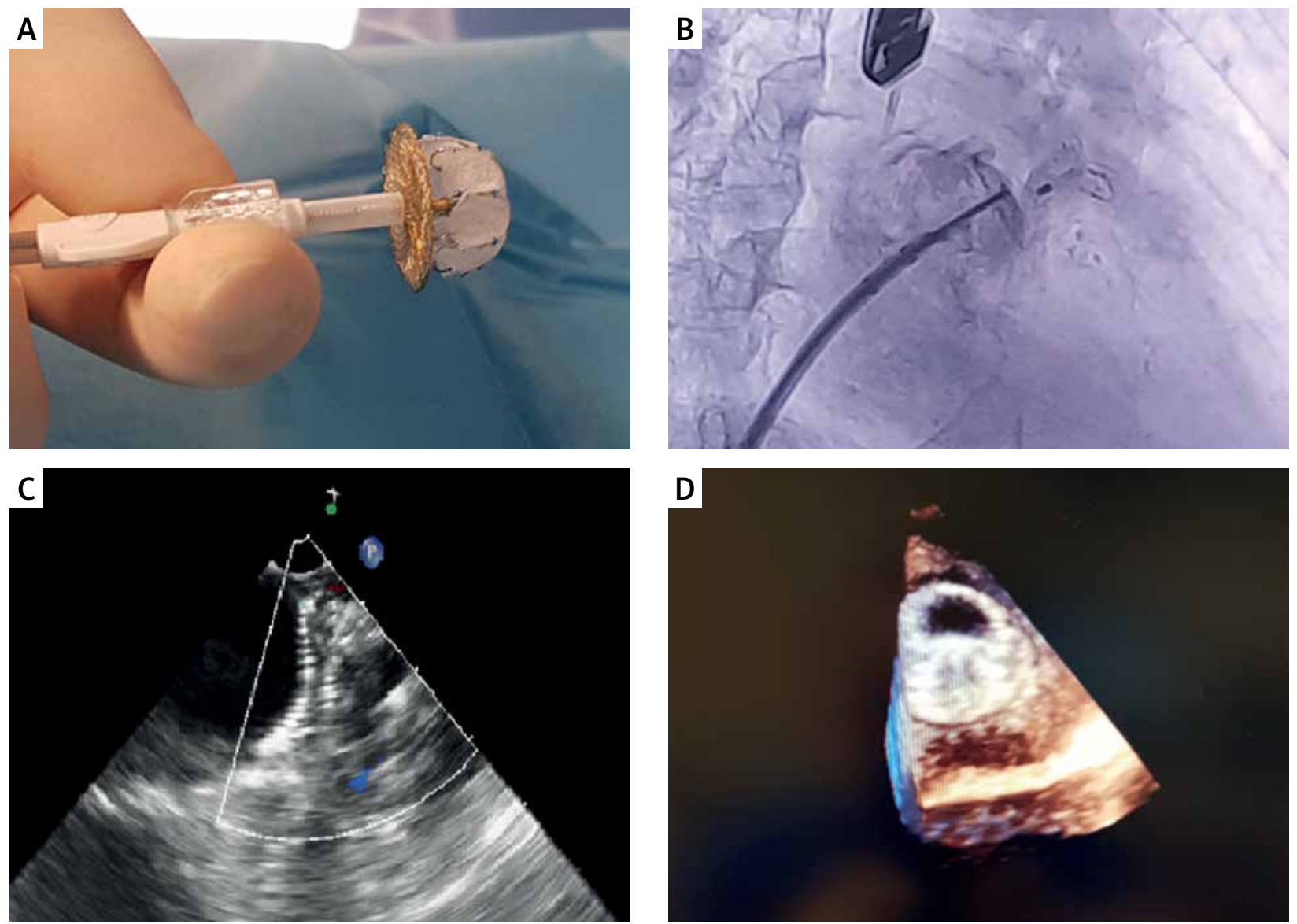

Figure 1. LAmbre occluder connected to the sheath (A), fluoroscopy (B), transesophageal echocardiography (C) and 3D echocardiography (D) of the LAmbre occluder after release and correctly placed in the left atrial appendage

acute exacerbation of chronic renal failure complicated by heart failure ( 5 months after the procedure); 1 case of out-of-hospital cardiac arrest ( 5 months after the procedure), 1 case of post neurosurgery complications due to cerebral artery aneurysm (15 months after the procedure) and in 1 case, the cause of death was unknown. There were no deaths connected to the procedure. Gastrointestinal bleeding were observed in 2 (8.34\%) cases. There was $1(4.17 \%)$ case of transient ischemic attack and $1(4.17 \%)$ case of stroke, 16 and 3 months after the procedure, respectively. In both cases control TEE examination showed no device thrombus. In the remaining patients follow-up TEE showed no device thrombi or LAA leaks (Table I).

\section{Discussion}

We present the first results in Poland of the LAAO procedure with LAmbre devices, with a $100 \%$ success rate and with no perioperative complications. From our initial experience, implantation is associated with a high success rate and good clinical outcomes.

Our results are similar to the most popular endocardial devices such as the Watchman or Amplatzer [4, 15].
Surprisingly, in our study, there was a larger number of postprocedural bleeding episodes, which were observed in $8.34 \%$ of patients, compared to other endocardial trials $[4,15]$. However, in our study, patients had a very high risk of bleeding (HAS-BLED score 4) and, in more than $60 \%$ of patients, the indication for LAAO was previous bleeding episodes. Of note, all bleeding episodes were among patients who were receiving antiplatelet therapy, and none were receiving OAC.

The observed mortality rate (16.6\%) was also higher than that reported in other endocardial device trials [4, 15]. However, none of the deaths were related to the procedure. Boersma et al. observed a $9.8 \%$ mortality rate at 12 months of observation in a Watchman device trial [4]. Importantly, all deceased patients were free of thrombus on the occluder and from postprocedural leak at 3-month and 6-month visits. Additionally, no device thrombi were observed, despite not receiving OAC, even in transient ischemic attack (TIA) and stroke patients. Similar data were obtained by Huang et al. [14].

The LAA morphology, including the LAA shape, ostium width and depth, plays a critical role in the choice of device. The most popular devices such as the Watchman, with its umbrella-like shape, should be avoided in 
Table I. Patient characteristics $(n=24)$

\begin{tabular}{|c|c|}
\hline Parameter & Results \\
\hline \multicolumn{2}{|l|}{ Age [years]: } \\
\hline Mean \pm SD & $71.63 \pm 8.17$ \\
\hline Range & $58-85$ \\
\hline Female & $33.33 \%$ \\
\hline $\mathrm{CHADS}_{2}$ score, mean $\pm \mathrm{SD}$ & $3.46 \pm 1.32$ \\
\hline $\mathrm{CHA}_{2} \mathrm{DS}_{2}-\mathrm{VASC}$ score, mean $\pm \mathrm{SD}$ & $4.96 \pm 1.46$ \\
\hline HAS-BLED score, median $\left(\mathrm{Q}_{1} ; \mathrm{Q}_{3}\right)$ & $4(3 ; 5)$ \\
\hline Congestive heart failure & $37.5 \%$ \\
\hline Hypertension & $100 \%$ \\
\hline Diabetes mellitus 2 & $37.5 \%$ \\
\hline Previous stroke & $54.17 \%$ \\
\hline Vascular disease & $54.17 \%$ \\
\hline Alcoholism & $4.17 \%$ \\
\hline \multicolumn{2}{|l|}{ Indication for LAAO procedure: } \\
\hline Gastrointestinal bleeding: & $37.5 \%$ \\
\hline While on NOAC & $16.66 \%$ \\
\hline While on VKA & $20.83 \%$ \\
\hline CNS bleeding: & $8.32 \%$ \\
\hline While on NOAC & $4.17 \%$ \\
\hline While on VKA & $4.17 \%$ \\
\hline Vitreous bleeding while on NOAC & $4.17 \%$ \\
\hline Respiratory tract bleeding while on VKA & $4.17 \%$ \\
\hline Urinary tract bleeding on NOAC & $4.17 \%$ \\
\hline Thrombus in LAA despite OAC & $4.17 \%$ \\
\hline Stroke/TIA despite OAC & $37.5 \%$ \\
\hline \multicolumn{2}{|l|}{ Pre-procedure anticoagulation: } \\
\hline \multicolumn{2}{|l|}{ Vitamin K antagonist: } \\
\hline Warfarin & $33.33 \%$ \\
\hline \multicolumn{2}{|l|}{ New oral anticoagulant: } \\
\hline Dabigatran & $41.67 \%$ \\
\hline Rivaroxaban & $20.83 \%$ \\
\hline LMWH & $4.17 \%$ \\
\hline \multicolumn{2}{|l|}{ LAA measurements [mm]: } \\
\hline LAA length & $26.8 \pm 5.8$ \\
\hline LAA orifice diameter & $23.1 \pm 4.9$ \\
\hline LAA landing zone diameter & $22.9 \pm 4.8$ \\
\hline \multicolumn{2}{|l|}{ Follow-up TEE (3 months/6 months): } \\
\hline Device dislodgment & $0 \% / 0 \%$ \\
\hline Thrombosis in LA & $0 \% / 0 \%$ \\
\hline Pericardial effusion & $0 \% / 0 \%$ \\
\hline Residual flow $>3 \mathrm{~mm}$ & $0 \% / 0 \%$ \\
\hline
\end{tabular}

shallow or multilobar LAAs. The second most commonly used device, the Amplatzer ACP, should be avoided in shallow LAAs because of the relatively proximal position of LAA implantation [13]. The LAmbre device is available in a larger range of device sizes (16-36 $\mathrm{mm}$ ) compared to the Watchman (21-30 mm) and ACP (16-34 mm) devices. It is also highly adaptive to many LAA sizes due to its smaller umbrellas with larger covers. Therefore, the larger choice of sizes and favorable device properties may make the LAmbre device more suitable for complex LAA anatomies, such as chicken wing or shallow LAA [13].

\section{Conclusions}

The LAAO procedure with the LAmbre device is associated with a high success rate and good short term clinical results.

\section{Conflict of interest}

The authors declare no conflict of interest.

\section{References}

1. Kirchhof P, Benussi S, Kotecha D, et al. 2016 ESC Guidelines for the management of atrial fibrillation developed in collaboration with EACTS. Eur Heart J 2016; 37: 2893-962.

2. Kirchhof P, Benussi S, Kotecha D, et al. 2016 ESC Guidelines for the management of atrial fibrillation developed in collaboration with EACTS. Eur J Cardiothorac Surg 2016; 50: e1-88.

3. Litwinowicz R, Konstanty-Kalandyk J, Goralczyk T, et al. Dabigatran level monitoring prior to idarucizumab administration in patients requiring emergent cardiac surgery. J Thromb Thrombolysis 2018; 45: 9-12.

4. Boersma LV, Ince H, Kische S, et al. Efficacy and safety of left atrial appendage closure with WATCHMAN in patients with or without contraindication to oral anticoagulation: 1-year followup outcome data of the EWOLUTION trial. Heart Rhythm 2017; 14: 1302-8.

5. Litwinowicz R, Bartus $M$, Ceranowicz P, et al. Stroke risk reduction after LAA occlusion in elderly patients with atrial fibrillation: long-term results. Pol Arch Intern Med 2018; 128: 327-9.

6. Bartus K, Myc J, Bartus M, et al. Rapid left atrial appendage thrombus formation in epicardial percutaneous LAA suture ligation with LARIAT. Adv Interv Cardiol 2018; 14: 435-7.

7. Bartus K, Litwinowicz R, Dziewierz A, et al. Coronary artery bypass grafting after left atrial appendage ligation - is anti-inflammatory treatment recommendation post LARIAT effective? Adv Interv Cardiol 2018; 14: 438-9.

8. Litwinowicz R, Bartus M, Burysz $M$, et al. Long term outcomes after left atrial appendage closure with the LARIAT device stroke risk reduction over five years follow-up. PLoS One 2018; 13: e0208710.

9. Chen S, Chun KJ, Bordignon S, et al. Left atrial appendage occlusion using LAmbre Amulet and Watchman in atrial fibrillation. J Cardiol 2019; 73: 299-306.

10. Litwinowicz R, Bartus M, Ceranowicz P, et al. Left atrial appendage occlusion for stroke prevention in diabetes mellitus patients with atrial fibrillation: long-term results. J Diabetes 2019; 11: 75-82.

11. Chen S, Schmidt B, Bordignon S, et al. Feasibility of percutaneous left atrial appendage closure using a novel LAmbre occluder 
in patients with atrial fibrillation: initial results from a prospective cohort registry study. J Cardiovasc Electrophysiol 2018; 29: 291-7.

12. Park JW, Sievert H, Kleinecke C, et al. Left atrial appendage occlusion with lambre in atrial fibrillation: initial European experience. Int J Cardiol 2018; 265: 97-102.

13. Reinsch N, Ruprecht U, Buchholz J, et al. Initial experience of percutaneous left atrial appendage closure using the LAmbre device for thromboembolic prevention. J Cardiovasc Med (Hagerstown) 2018; 19: 491-6.

14. Huang H, Liu Y, Xu Y, et al. Percutaneous left atrial appendage closure with the lambre device for stroke prevention in atrial fibrillation: a prospective, multicenter clinical study. JACC Cardiovasc Interv 2017; 10: 2188-94.

15. Landmesser U, Schmidt B, Nielsen-Kudsk JE, et al. Left atrial appendage occlusion with the AMPLATZER Amulet device: periprocedural and early clinical/echocardiographic data from a global prospective observational study. Eurointervention 2017; 13: 867-76. 